\title{
Notícias do Levantamento de Recursos e Necessidades de Enfermagem na Revista Brasileira de Enfermagem (1955-1958)
}

\author{
News of the Inquiry about Nursing Needs and Resources in the Brazilian Journal of Nursing (1955-1958) \\ Noticias del Levantamiento de Necesidades y Recursos de Enfermería en la \\ Revista Brasileña de Enfermería (1955-1958)
}

\author{
Daniela Vieira Malta', Laís de Araújo Pereira', Tânia Cristina Franco Santos' \\ ' Universidade Federal do Rio de Janeiro, Escola de Enfermagem Anna Nery, \\ Programa de Pós-Graduação em Enfermagem. Rio de Janeiro-RJ, Brasil.
}

Submissão: 16-12-2012 Aprovação: 15-07-2014

\section{RESUMO}

Estudo Histórico Social que tem como objeto notícias sobre o Levantamento de Recursos e Necessidades de Enfermagem no Brasil, publicadas na Revista Brasileira de Enfermagem entre 1955 e 1958. A fonte primária foi constituída pelos exemplares da Revista Brasileira de Enfermagem, publicados dentro do recorte temporal do estudo. As fontes secundárias foram constituídas por livros, artigos, dissertações e teses relativas à história da Enfermagem. A análise dos dados teve apoio das fontes secundárias e do pensamento do sociólogo Pierre Bourdieu. Os dados evidenciaram que a Revista Brasileira de Enfermagem, além de oportunizar a divulgação de notícias acerca do Levantamento, proporcionou visibilidade ao mesmo mediante a veiculação dessas notícias e, por fim, teve o efeito simbólico de conferir poder e prestígio à Enfermagem Brasileira.

Descritores: Enfermagem; História da Enfermagem; Memória.

\section{ABSTRACT}

Social historical study that has as object news related to the Assessment of the Resources and Needs of Nursing in Brazil published in the Revista Brasileira de Enfermagem between 1955 and 1958. The primary source is constituted of copies of Revista Brasileira de Enfermagem published within the selected period of the study. The secondary sources are constituted of books, papers, dissertations and thesis related to the Nursing history. The data analysis was supported by the secondary sources and the thought of the sociologist Pierre Bourdieu. The results evidenced that Revista Brasileira de Enfermagem, in addition to making possible the dissemination of news about the Assessment provided visibility to it and, at last, had the symbolic effect of giving power and prestige to the Brazilian Nursing.

Key words: Nursing; History of Nursing; Memory.

\section{RESUMEN}

Estudio Histórico Social que tiene como objeto noticias referentes al Levantamiento de Recursos y Necesidades de Enfermería en Brasil publicadas en la Revista Brasileira de Enfermagem entre 1955 y 1958. La fuente primaria se constituye de los ejemplares de la Revista Brasileira de Enfermagem publicados dentro del recorte temporal do estudio. Las fuentes secundarias están constituidas de libros, artículos disertaciones y tesis relativas a la historia de la Enfermería. El análisis de los datos tuvo apoyo de las fuentes secundarias y del pensamiento del Sociólogo Pierre Bourdieu. Los resultados evidencian que la Revista Brasileira de Enfermagem, además de posibilitar la divulgación de noticias acerca del Levantamiento proporcionó visibilidad al mismo mediante la divulgación de esas noticias y, por fin, tuve el efecto simbólico de conferir poder y prestigio a la Enfermería Brasileña.

Palabras clave: Enfermería; Historia de la Enfermería; Memoria. 


\section{INTRODUÇÃO}

As notícias sobre o Levantamento de Recursos e Necessidades de Enfermagem no Brasil publicadas na Revista Brasileira de Enfermagem (REBEn) foram o objeto desse estudo. O recorte temporal compreendeu os anos entre 1955 e 1958, abrangendo assim o período de elaboração do referido Levantamento pela Associação Brasileira de Enfermagem (ABEn). Vale recuar no tempo e mencionar que a $A B E n$ foi criada em 12 de agosto de 1926, por um grupo de enfermeiras, ex-alunas da Escola de Enfermagem Anna Nery (EEAN), no intuito de concretizar a ideia de que, para uma profissão progredir, precisava de uma associação e de uma revista ${ }^{(1)}$.

Durante décadas, os objetivos que nortearam os trabalhos da Associação foram os de lutar pelo desenvolvimento da Enfermagem no Brasil e o fortalecimento de um espírito de corpo, privilegiando o "status" social e cultural, característica de um período em que a Enfermagem profissional estava se instalando no país, seguindo o modelo nightingaleano ${ }^{(2)}$. Ao longo desses anos, a ABEn construiu um significativo patrimônio histórico, cultural e físico. No que interessa a este estudo, é válido citar a criação do Congresso Brasileiro de Enfermagem (CBEn) e da REBEn.

O primeiro CBEn, à época denominado Congresso Nacional de Enfermagem, ocorreu em 1947 na cidade de São Paulo e, desde então, vem sendo realizado anualmente, exceto nos anos de 1953 e 1961, pois, em 1953, hospedou o X Congresso Quadrienal do Conselho Internacional de Enfermeiras (ICN) em Petrópolis e, em 1961, ocorreu no Rio de Janeiro o Congresso do Comitê Internacional Católico de Enfermeiros e Assistentes Médicos Sociais (CICIAMS) ${ }^{(1)}$.

Esses congressos vêm congregando profissionais de todo o país, representando um importante espaço de discussão dos mais variados temas de interesse para profissão. Ao longo dos anos, as recomendações derivadas das discussões contribuíram para impulsionar a realização de importantes ações em prol do desenvolvimento da Enfermagem brasileira.

Em sua sétima edição, em 1954, o CBEn trouxe como uma de suas recomendações a necessidade da realização de uma pesquisa para avaliar a situação da Enfermagem no país. Foi a partir dessa recomendação que a ABEn iniciou a mobilização para realização de um Levantamento sobre Recursos e Necessidades de Enfermagem no Brasil, o qual foi concluído em 1958, sendo os principais resultados apresentados no XI CBEn, do mesmo ano.

A REBEn, lançada em 20 de maio de 1932, com a denominação de Annaes de Enfermagem, foi, até 1967, ano de criação da Revista da Escola de Enfermagem da Universidade de São Paulo (USP), o principal veículo de socialização da produção intelectual da Enfermagem, representando o primeiro espaço no cenário brasileiro em que as enfermeiras veicularam seus conhecimentos, com vistas ao estabelecimento de uma comunidade científica de enfermagem, e a estruturação de seu campo científico ${ }^{(3)}$. Essa estratégia foi eficaz porque a utilização da revista como espaço de comunicação representou a possibilidade de fazer ver, de levar a existência, de fazer reconhecer e, portanto, de nomear, as figuras prestigiosas da
ABEn implicadas com a elaboração do Levantamento. Essa estratégia agregava crédito simbólico ao projeto em curso.

No que tange à relação da Revista com o Levantamento de Recursos e Necessidades de Enfermagem no Brasil, cumpre relevar que a REBEn foi o principal veículo de divulgação dessa importante investigação. Os editoriais e a seção de Notícias e Comentários da revista divulgavam periodicamente o andamento da Pesquisa, bem como sua repercussão na mídia nacional e internacional e nos eventos ligados à Enfermagem.

Diante da problemática apresentada foram formulados os seguintes objetivos para este estudo: descrever as circunstâncias que ensejaram a elaboração do Levantamento de Recursos e Necessidades de Enfermagem no Brasil; identificar as notícias sobre o caminhar deste Levantamento na REBEn, no período de 1955 a 1958, e analisar a importância dessas notícias para a realização do referido Levantamento.

\section{METODOLOGIA}

Trata-se de um estudo histórico-social, cujas fontes primárias foram as edições da REBEn, referentes ao período de 1955 a 1958, localizadas no Centro de Documentação da EEAN da Universidade Federal do Rio de Janeiro (UFRJ). Nesse período a REBEn era publicada trimestralmente e, sendo assim, no período em estudo, foram localizadas 16 revistas. A coleta de dados foi realizada no mês de abril de 2012. As fontes secundárias inerentes à temática do estudo, localizadas na Biblioteca Setorial da EEAN-UFRJ, foram constituídas por artigos, dissertações, teses e livros.

Para análise das fontes primárias foram realizados os seguintes procedimentos: seleção de todas as edições da REBEn, referentes aos anos 1955, 1956, 1957 e 1958; seleção de notícias sobre o Levantamento de Recursos e Necessidades de Enfermagem no Brasil publicadas na "Seção de Notícias e Comentários"; organização dessas notícias, contemplando uma breve descrição do conteúdo das mesmas.

A análise dos dados, em consonância com o método histórico, comportou o levantamento dos dados, avaliação crítica e a análise consubstanciada desses dados pelo conhecimento produzido sobre o tema ${ }^{(4)}$. Além disso, o conceito de capital simbólico do sociólogo francês Pierre Bourdieu representou uma importante ferramenta analítica para o entendimento das estratégias empreendidas pelas responsáveis pela elaboração do Levantamento de Recursos e Necessidades de Enfermagem no Brasil para angariar capital eficiente à viabilização do projeto.

O conceito de capital, emprestado da economia, tem papel essencial para o pensamento de Pierre Bourdieu. No que se refere ao conceito de capital simbólico, este diz respeito ao prestígio ou boa reputação que um indivíduo ou instituição possuí num campo específico ou na sociedade em geral ${ }^{(5)}$. Esse conceito se refere, em outras palavras, ao reconhecimento obtido pelos indivíduos ou instituições.

O projeto que deu origem ao presente estudo foi aprovado pelo Comitê de Ética e Pesquisa da EEAN- Hospital São Francisco de Assis (Protocolo 063-2011), em 27 de setembro de 2011.

O presente estudo se justifica por sua contribuição à História da Enfermagem Brasileira e ao avanço do conhecimento 
produzido sobre o tema, uma vez que o referido Levantamento veio a se constituir em um marco da pesquisa em enfermagem no Brasil, consagrando uma "geração das enfermeiras autodidatas" ${ }^{\prime(6)}$, pelo fato de terem sido precursoras de estudos científicos na área da Enfermagem. Ademais, não obstante a importância do Levantamento de Recursos e Necessidades de Enfermagem no Brasil, os estudos históricos publicados mais recentemente fazem poucas menções ao Levantamento, cuja divulgação à época de sua conclusão também foi prejudicada devido ao número restrito de exemplares do Relatório Final ${ }^{(7)}$.

Do ponto de vista social, a relevância do estudo consiste na possibilidade de ratificar a importância da ABEn para o desenvolvimento da profissão, bem como sua contribuição à história, como lugar de memória da Enfermagem Brasileira.

\section{RESULTADOS E DISCUSSÃO}

\section{O Levantamento de Recursos e Necessidades de Enferma- gem no Brasil}

A justificativa da ABEn para realizar um trabalho de âmbito nacional como o Levantamento de Recursos e Necessidades de Enfermagem no Brasil teve apoio em vários argumentos, entre as quais se destacam os seguintes: a vontade de atender aos vários pedidos de informação direcionados à Associação, no sentido de verificar o número exato de enfermeiros existentes e a necessidade de se conhecer melhor a situação da Enfermagem nos seus diferentes aspectos, de forma a dispor de informações que possibilitassem recomendar medidas para corrigir as deficiências quantitativas e qualitativas do campo da Enfermagem ${ }^{(8)}$. Era indispensável saber as necessidades do país em relação ao preparo dos profissionais de enfermagem; a possibilidade de absorção de profissionais de enfermagem no futuro próximo; o recurso necessário à formação dos profissionais de enfermagem; as razões da atitude indiferente da sociedade para com a enfermagem e ainda como vencer essa atitude ${ }^{(9)}$.

A ABEn reconhecia a importância desses dados para o desenvolvimento da profissão, mediante a possibilidade de utilizá-los como argumentos para discutir com os legisladores, governantes, pessoas autorizadas e as próprias enfermeiras. Surge então a ideia de se fazer um estudo acurado, intenso e cuidadoso da situação que a Enfermagem se encontrava ${ }^{(9)}$. Assim, no âmbito do VII CBEn, realizado em agosto de 1954, em São Paulo (Gestão 1952-1954, Presidente Glete de Alcântara), um dos temas discutidos foi o Estudo das Necessidades de Enfermagem no Brasil.

Nesse Congresso, dois importantes acontecimentos deram impulso à realização do Levantamento. $\mathrm{O}$ primeiro se refere à proposta da Diretoria da Divisão de Educação da ABEn, representada por Haydeè Guanais Dourado, que propôs que a Associação deveria "estudar as necessidades de enfermagem no país e os níveis de formação profissional para fazer frente às necessidades ${ }^{\prime(1)}$. O segundo, refere-se à proposta da Comissão Especial de Levantamento Estatístico da ABEn, para que fosse recomendada à Associação a manutenção atualizada de seu arquivo de informações, com vistas a colaborar com o planejamento de serviços médico- sanitários e com o ensino de enfermagem no país, mediante o fornecimento de dados exatos ${ }^{(6)}$.
Tais recomendações ensejaram providências com vistas à obtenção de recursos financeiros e humanos. Esse fato é comprovado no Relatório anual da Presidente da ABEn Maria Rosa S. Pinheiro, publicado na REBEn em 1955. No documento, há a informação de que a ABEn, vinha trabalhando desde agosto de 1954, para cumprir a recomendação do VII CBEn, ou seja, estava se empenhando na obtenção de recursos, ressaltando que a Fundação Rockfeller havia se interessado pelo assunto, prontificando-se a financiar o projeto ${ }^{(10)}$.

A elaboração propriamente dita do estudo iniciou-se em 1955. Os dados foram colhidos a partir de 1956 e o Relatório Final do Levantamento de Recursos e Necessidades de Enfermagem no Brasil foi entregue em 30 de outubro de 1958, sendo esse organizado em cinco partes: "Enfermeiros em atividade e inativos", "Enfermagem Hospitalar", "Enfermagem em Saúde Pública", "Escolas e Cursos de Auxiliar de Enfermagem" e "Escolas de Enfermagem"(7).

Na redação do Relatório Final, colaboraram Maria Lourdes Verderese, Olga Verderese e Haydée Guanais Dourado. Foram registradas no mesmo 46 recomendações dirigidas ao Ministério de Educação, Ministério da Saúde, às Universidades e legisladores, aos serviços de enfermagem em unidades sanitárias e hospitalares, à Conferência dos Religiosos do Brasil, às instituições que mantinham escolas de enfermagem, às próprias escolas de enfermagem e de auxiliar de enfermagem e à $A B E n^{(11)}$.

A Revista Brasileira de Enfermagem como veículo de divulgação do Levantamento de Recursos e Necessidades de Enfermagem no Brasil

As notícias referentes ao Levantamento de Recursos e Necessidades de Enfermagem no Brasil passaram a constar na Seção de Notícias e Comentários da REBEn a partir de 1956. Foram identificadas 16 notícias acerca do Levantamento nos anos de 1956 a 1958. Dessas 16 notícias, 05 são acompanhadas de fotografias. Quanto aos assuntos abordados, 09 discorrem sobre as doações provenientes de instituições prestigiosas, concessões de entrevistas, participações em congressos e visitas ilustres - denotando o prestígio da ABEn e, por conseguinte o crédito simbólico atribuído ao Levantamento; e 07 descrevem as principais atividades realizadas em prol da execução do Levantamento, fazendo uma espécie de prestação de contas às pessoas e instituições que de alguma forma estavam envolvidas no estudo.

Nas edições referentes ao ano XI, ou seja, 1956 foram publicadas 05 notícias acerca do Levantamento, sendo 02 notícias no número 1, mês março; 01 notícia no número 03 , mês setembro; e por fim 02 notícias no número 04, mês dezembro.

Nas edições referentes ao ano XII, ou seja, 1957 foram publicadas um total de 06 notícias referentes ao Levantamento, sendo 02 notícias no número 01 , mês março; 03 notícias no número 03, mês setembro; e por fim, 01 notícia, no número 04, mês dezembro.

Nas edições referentes ao ano XIII, ou seja, 1958 foram publicadas um total de 05 notícias referentes ao Levantamento, sendo 02 notícias no número 01 , mês março; 01 notícia no número 02, mês junho; e por fim, 02 notícias no número 03 , mês setembro. 
Nas edições da revista referentes ao ano de 1955 não houve publicações sobre o Levantamento. Nos anos subsequentes, a distribuição de notícias nos números da revista foi equilibrada. Depreende-se que o silêncio sobre o desenvolvimento do projeto no ano de 1955 se deve ao fato de que a primeira reunião para deliberar as primeiras ações no sentido de organizar o Levantamento só ocorreu em 8 de julho de 1955. Provavelmente por isso, na edição de março de 1956, a REBEn publicou as primeiras duas notícias sobre o Levantamento. Nessa edição, ao mesmo tempo em que eram prestadas informações sobre as primeiras iniciativas em prol do Levantamento, também se reafirmava o compromisso com o desenvolvimento da profissão, mediante a divulgação da pesquisa, contribuindo para o reconhecimento da competência e autoridade científica das enfermeiras nos assuntos ligados à sua prática profissional. $\mathrm{O}$ seguinte excerto evidencia tal compromisso: "A Revista Brasileira de Enfermagem noticiará o andamento dos trabalhos"(12).

A veiculação de informações acerca do prestígio e da visibilidade que o Levantamento estava proporcionando à Enfermagem Brasileira, por meio da ABEn, reafirmava o valor e a credibilidade da pesquisa que estava em andamento. Essa estratégia tinha o intuito de transmitir confiança e fazer com que o grupo colaborasse na etapa de coleta de dados do Levantamento, que para seu êxito dependia da transmissão de dados fidedignos. $\mathrm{O}$ trecho a seguir evidencia essa estratégia:

Está em fase preparatória o trabalho inicial dos inquéritos sobre enfermagem. Como primeira providência foi instalado o Centro de Levantamento de Necessidades e Recursos de Enfermagem, estabelecido, graças ao oferecimento da Fundação Rockfeller, em sua própria sede [...] As Sras. Zilda Carvalho Hughes e Haydée Guanais Dourado, em regime de tempo integral, dedicam-se a esse grande empreendimento da ABEn. A Sra. Maria Palmiro Tito de Moraes, da OMS - Repartição Sanitária Panamerica, chegada ao Brasil em março [...] é um dos assessores do levantamento. A Sra. Maria Rosa, Presidente da Comissão Executiva [...] esteve na cidade em março a convite da Fundação Rockfeller, a fim de tomar parte em deliberações preliminares, juntamente com outras autoridades que cooperam com o levantamento. Tem mensalmente reuniões ora no Rio de janeiro, ora em São Paulo, acertando as medidas principais. Todas as seções da ABEn e por intermédio, todos os seus associados deverão tomar parte nos trabalhos [...] É, pois, de interesse comparecerem às reuniões mensais das Seções, para aí terem comunicação do assunto. A Revista Brasileira de Enfermagem igualmente noticiará o andamento dos trabalho ${ }^{(12)}$.

Outra estratégia utilizada pela ABEn foi a divulgação de que a Fundação Rockfeller estava financiando o projeto: "A presidente também noticiou em primeira mão [...] que a associação obteve uma doação da Fundação Rockfeller para esse importante estudo que nos deverá revelar o estado atual da Enfermagem"(12). Note-se que desde 1920 a Fundação Rockfeller colaborava com o Brasil com investimentos na área de saúde pública, inclusive financiando a Missão Parsons.
Uma oferta dessa monta, concedida pela prestigiosa Fundação Rockfeller, evidencia a credibilidade da ABEn e da Enfermagem Brasileira perante uma instituição internacional o que denota o prestígio da Associação, agregando poder e prestígio à Enfermagem Brasileira. Vale ressaltar que, a partir do financiamento da Fundação Rockfeller, outras instituições decidiram apoiar o projeto, evidenciando que o capital simbólico da Fundação agregou lucros simbólicos ao projeto da ABEn. Assim, o Levantamento de Recursos e Necessidades de Enfermagem no Brasil pôde contar com a assessoria técnica da Organização Mundial de Saúde (OMS) e do Instituto Brasileiro de Geografia e Estatística (IBGE), além da colaboração de outras importantes instituições públicas e particulares, civis e religiosas ${ }^{(1)}$.

Outro recurso utilizado foi a divulgação do capital social e simbólico do grupo, particularmente na fase final do trabalho, quando foi noticiado na REBEn que a revista norte-americana American Journal of Nursing divulgou que a ABEn estava realizando um Levantamento de Recursos e Necessidades de Enfermagem no Brasil(13). Ademais, a Revista Brasileira de Enfermagem também noticiou que o Centro de Levantamentos havia sido visitado por figuras ilustres do campo da saúde, destacando a visita de Marcolino Gomes Candau, então Diretor Geral da Organização Mundial da Saúde ${ }^{(14)}$.

Os assuntos abordados na seção de Notícias e Comentários comprovam a dimensão da pesquisa realizada e a visibilidade tanto nacional quanto internacional que a mesma trouxe para a Enfermagem Brasileira. As notícias foram recorrentes no sentido de informar o cumprimento do cronograma proposto para o estudo, como se observa no trecho que segue: "em fevereiro deverá ser concluída em todo Brasil a coleta de dados do Centro de Levantamento de Recursos e Necessidades de Enfermagem [...]. O relatório final dos trabalhos é esperado para julho de 1958”(15).

A ampla divulgação do processo de execução do Levantamento de Recursos e Necessidades de Enfermagem no Brasil conferiu poder à $A B E n$, visto que as relações de comunicação são sempre relações de poder que dependem na forma e no conteúdo, do poder material ou simbólico acumulado pelos indivíduos ou instituições e que permitem acumular poder material ou simbólico ${ }^{(16)}$ que, no caso da Associação se materializou pela obtenção de doação orçamentária e pelo reconhecimento social evidenciado através da participação de representantes de instituições prestigiosas nacionais e internacionais.

Na edição da REBEn de outubro de 1964, ou seja, seis anos após a conclusão do Levantamento, foi publicado um artigo escrito pela enfermeira Ermengarda de Faria Alvim, Diretora de Divisão de Enfermagem da Fundação do Serviço Especial de Saúde Pública à época intitulado Levantamento de Recursos e Necessidades de Enfermagem. Nesse artigo, a autora considera o Levantamento um dos trabalhos mais importantes já realizados pela $A B E n$. Cita a motivação e as finalidades do mesmo, descreve todas as etapas de coleta de dados e dos principais desdobramentos do mesmo. Ao final do artigo ela conclui que um dos grandes méritos dessa Pesquisa foi ter aberto o caminho para estudos dessa natureza e ter demonstrado que à Associação teve condições para realizá-la ${ }^{(8)}$.

No que tange as medidas e providências que foram tomadas após a divulgação dos resultados do Levantamento, a autora 
destacou: melhorias levadas a efeito no ensino da Enfermagem; designação de um elemento coordenador das atividades de enfermagem em muitos serviços hospitalares e de saúde pública; melhor aproveitamento dos elementos de enfermagem de todos os níveis e definição de suas atribuições e melhor compreensão da necessidade de treinamento de pessoal( ${ }^{(8)}$.

\section{CONSIDERAÇÕES FINAIS}

A REBEn, além de oportunizar a divulgação de notícias acerca do Levantamento de Recursos e Necessidades de
Enfermagem no Brasil, proporcionou visibilidade ao estudo mediante a veiculação de suas notícias. Essa relevante divulgação na Revista pode ser considerada uma estratégia das enfermeiras vinculadas ao projeto em manter um canal de comunicação, fazendo com que o Levantamento permanecesse vivo na memória dos leitores.

As notícias publicadas na REBEn referentes ao Levantamento tiveram efeito simbólico de conferir poder e prestígio à $A B E n$, mediante o reconhecimento de sua competência em realizar um estudo de grande porte com financiamento de uma instituição internacional.

\section{REFERÊNCIAS}

1. Carvalho AC. Associação Brasileira de Enfermagem 19261976: documentário. Brasília (DF): ABEn; 1976.

2. Barreto IS, Oliveira IRS, Lima MG. Associação Brasileira de Enfermagem: 70 anos de lutas e conquistas. Esc Anna Nery Rev Enferm [Internet]. 1997 [acesso em 16 de dezembro de 2012];1(1):23-31. Disponível em: http://bases.bireme.br/cgi-bin/wxislind.exe/iah/online/? lsisScript =iah/iah. xis\&src $=$ google $\&$ base $=$ LILACS\&lang $=$ p\&nextAction $=I$ nk\&exprSearch $=284419$ \&indexSearch $=$ ID

3. Santos TCF, Gomes MLB. Nexos entre pós-graduação e pesquisa em Enfermagem no Brasil. Rev Bras Enferm. 2007;60(1):92-5.

4. Padilha MICS, Borenstein MS. O método da pesquisa histórica na enfermagem. Texto \& Contexto Enferm [Internet]. 2005 [acesso em 16 de dezembro de 2012];14(4):57584. Disponível em: http://www.scielo.br/pdf/tce/v14n4/ a15v14n4.pdf

5. Bourdieu P. Os usos sociais da ciência: por uma sociologia clínica do campo científico. São Paulo (SP): Ed UNESP; 2004.

6. Brandão EM. A Formação do campo científico de enfermagem no Brasil: sociologia da geração de pesquisadoras pioneiras - 1935-1958 [tese]. Rio de Janeiro (RJ): Escola de Enfermagem Anna Nery, Universidade Federal do Rio de Janeiro; 1999.

7. Secaf V, Sanna MC. "Levantamento de recursos e necessidades de enfermagem no Brasil" - um documento da década de 50 do século XX. Rev Bras Enferm. 2003;56(3):315-7.

8. Alvim EF. Levantamento de Recursos e Necessidades de
Enfermagem. Rev Bras Enferm. 1964;5:301-4.

9. Pinheiro MR. Razões para realização de um inquérito de recursos e necessidades de enfermagem. In: Anais do Seminário Didático Internacional sobre Levantamentos de Enfermagem, 1959 jul; Salvador. Washington (DC): Pan American Sanitary Bureau; 1959. p. 5-9.

10. Associação Brasileira de Enfermagem. Relatório anual da Presidente. Rev Bras Enferm. 1955;8(3).

11. Associação Brasileira de Enfermagem. Levantamento de recursos e necessidades de enfermagem no Brasil: o compromisso histórico da ABEn no desenvolvimento da pesquisa e da produção do conhecimento [Internet] Brasília (DF): ABEn; 2004 [acesso em 16 de dezembro de 2012]. Disponível em: http://www.abennacional.org.br/centrodememoria/levantamentoderecursos.pdf.

12. Associação Brasileira de Enfermagem. Noticiário - Doação da Fundação Rockefeller proporciona à ABEn promover um levantamento de necessidades e recursos de enfermagem. Rev Bras Enferm. 1956;9(1):46.

13. Associação Brasileira de Enfermagem. Noticiário - O Levantamento nas Páginas da AJN. Rev Bras Enferm. 1958;11(1):94.

14. Associação Brasileira de Enfermagem. Noticiário - Recebe Visitas Ilustres o Centro de Levantamentos da ABEn. Rev Bras Enferm. 1957;10(3):295.

15. Associação Brasileira de Enfermagem. Noticiário - Centro de Levantamentos de Recursos e Necessidades de Enfermagem. Rev Bras Enferm. 1958;11(1):95.

16. Bourdieu P. O poder simbólico. Rio de Janeiro (RJ): Bertrand; 2001. 